\title{
Visual Outcomes Based on Early Response to Anti-Vascular Endothelial Growth Factor Treatment for Diabetic Macular Edema
}

\author{
Yoshito Koyanagi Shigeo Yoshida Yoshiyuki Kobayashi Yuki Kubo \\ Takahito Nakama Keijiro Ishikawa Shintaro Nakao Toshio Hisatomi \\ Yasuhiro Ikeda Yuji Oshima Tatsuro Ishibashi Koh-hei Sonoda \\ Department of Ophthalmology, Graduate School of Medical Sciences, Kyushu University, Fukuoka, Japan
}

\section{Keywords}

Anti-vascular endothelial growth factor - Diabetic macular edema - Optical coherence tomography · Visual acuity

\begin{abstract}
Objective: To examine the relationship between early response to anti-vascular endothelial growth factor (VEGF) treatment and visual prognosis. Methods: We retrospectively separated 20 patients with persistent diabetic macular edema (DME) into two responder status groups based on the reduction of central macular thickness (CMT) from baseline to month 3: a delayed responder group (DRG) ( $\leq 25 \%$ CMT reduction, $n=11$ ) and an immediate responder group (IRG) (>25\% CMT reduction, $n=14$ ). We also separated the patients into two responder status groups based on the logarithm of the minimum angle of resolution (logMAR) best-corrected visual acuity (BCVA): a visual nonimprovement group (VNIG) ( $\geq 0$ logMAR BCVA improvement, $n=11$ ) and a visual improvement group (VIG) $(<0$ logMAR BCVA improvement, $n=14)$. Finally, we assessed the correlations between logMAR BCVA changes from baseline to month $3\left(\triangle B C V A_{M 3}\right)$ and those from baseline to month $12\left(\triangle B C V A_{M 12}\right)$. Results: At month 12, BCVA was significantly more improved in the VIG than the VNIG $(p<0.005)$, but was not significantly dif-
\end{abstract}

ferent between the DRG and the IRG ( $p=0.75)$. The Pearson correlation coefficient showed a significant relationship between $\triangle \mathrm{BCVA}_{\mathrm{M} 3}$ and $\triangle \mathrm{BCVA}_{\mathrm{M} 12}(r=0.60, p<0.005)$. Conclusions: $B C V A$ showed significantly greater improvement in the VIG than in the VNIG. $\triangle B C V A_{M 3}$ may predict the visual outcome at month 12 in DME patients treated with antiVEGF drugs.

(c) 2017 S. Karger AG, Basel

\section{Introduction}

Diabetic macular edema (DME) is a leading cause of decreased vision in patients with diabetic retinopathy [1]. Various treatment options are available for the management of DME [2]. Vascular endothelial growth factor (VEGF) is an important mediator of the abnormal vascular permeability in eyes with DME $[3,4]$, and several clinical trials have confirmed that intravitreal injections of anti-VEGF antibodies have been established as the standard in the treatment of DME [5-15].

However, anti-VEGF therapy for DME does present some problems. One of them is its high cost. Schmid et al. [16] revealed that the overall treatment cost is almost twice as high for DME patients compared to patients with

\section{KARGER}

(c) 2017 S. Karger AG, Basel

E-Mail karger@karger.com

www.karger.com/oph
Shigeo Yoshida, $\mathrm{MD}, \mathrm{PhD}$

Department of Ophthalmology, Graduate School of Medical Sciences

Kyushu University, 3-1-1 Maidashi, Higashi-ku

Fukuoka 812-8582 (Japan)

E-Mail yosida@eye.med.kyushu-u.ac.jp 
age-related macular degeneration or retinal vein occlusion, because DME patients have other clinical conditions (diabetes mellitus and its complications) in addition to DME. The cost of anti-VEGF therapy is thus one of the major financial burdens for DME patients. This may have been why DME patients received an average of 2.2-3.6 bevacizumab injections annually, markedly fewer than the number received by patients in major clinical trials of ranibizumab [17]. Clinicians should consider switching treatment options when a patient has failed anti-VEGF treatment, and it would thus be helpful to be able to predict whether or not a patient will respond to anti-VEGF drugs in the early phase of treatment.

Regarding the relationship between visual outcomes and early response to anti-VEGF treatment for DME, various authors $[7,18,19]$ reported an analysis of data from the RIDE and RISE trials. Pieramici et al. [18] reported an analysis of data from the RIDE and RISE trials [7, 19]. They found that DME patients who showed a delayed anatomic response after three ranibizumab injections had an improvement in visual acuity at month 24 similar to that of DME patients who showed an immediate anatomic response [19]. This post hoc analysis showed that anatomic outcomes at month 3 did not affect visual outcomes at month 24 and supported continuing ranibizumab therapy for DME even when patients showed a delayed anatomic response to treatment. In practice, however, DME patients rarely receive monthly intravitreal injections, and thus these results must be confirmed in a real-world clinical setting.

In the present study, we assessed the effects of shortterm responses to anti-VEGF treatment for DME on visual outcomes in routine clinical practice.

\section{Methods}

All the patients were examined at Kyushu University Hospital (Fukuoka, Japan) and were followed up for at least 12 months between February 2014 and April 2016. This study was a retrospective review of consecutive patients who had center-involved DME and received intravitreal injections of anti-VEGF drugs. We compared the data collected before the injections with the data obtained at month 12 after the injections.

The best-corrected visual acuity (BCVA) was measured with the Landolt decimal visual acuity chart (CV-6000, Tomey, Nagoya, Japan, or AVC-36, Kowa, Nagoya Japan) at $5 \mathrm{~m}$ or with single Landolt test cards (HP-1258; Handaya, Tokyo, Japan) and converted to logarithm of the minimum angle of resolution (logMAR) units.

All patients were examined after induction of pharmacological mydriasis. The $512 \times 128$ macular cube used for the Cirrus protocol (Carl Zeiss Meditec, Dublin, CA, USA) was applied for optical coherence tomography (OCT) image acquisition. The mean thickness of all the points within a 1-mm diameter internal circle was defined as the central macular thickness (CMT).

Prognosis of Anti-VEGF Treatment in Diabetic Macular Edema
In this retrospective analysis, 25 eyes of 20 patients with persistent DME were studied. We separated the patients into two responder status groups based on CMT or logMAR BCVA changes from baseline after three injections of anti-VEGF drugs. In the classification by CMT changes from baseline to month $3\left(\Delta \mathrm{CMT}_{\mathrm{M} 3}\right)$, patients were classified into a delayed responder group (DRG) (i.e., patients with $\leq 25 \%$ CMT reduction after three injections of anti-VEGF drugs, $n=11$ ) and an immediate responder group (IRG) (patients with $>25 \%$ CMT reduction after three injections of anti-VEGF drugs, $n=14)$. In the classification by logMAR BCVA changes from baseline to month $3\left(\triangle \mathrm{BCVA}_{\mathrm{M} 3}\right)$, patients were classified into a visual nonimprovement group (VNIG) (i.e., patients with $\geq 0$ logMAR BCVA improvement after three injections of anti-VEGF drugs, $n=11$ ) and a visual improvement group (VIG) (patients with $<0$ logMAR BCVA improvement after three injections of anti-VEGF drugs, $n=14)$. We examined the differences in visual outcomes at month 12 between the pairs of groups for both classifications.

Eyes that were excluded had alterations in the eye that could prevent an improvement in BCVA, active intraocular inflammation or infection in one or both eyes, uncontrolled glaucoma in either eye, or panretinal photocoagulation (PRP) within 6 months or focal/grid laser photocoagulation within 3 months prior to the beginning of this study. Patients were also excluded if they had had prior treatment with antiangiogenic drugs in the studied eye in the 3 months before the injections of anti-VEGF drugs, had switched therapy from intravitreal ranibizumab or intravitreal aflibercept injections, or underwent a vitrectomy, cataract extraction, or steroid injections during the course of the present study. Fluorescein angiography was used at baseline to rule out macular ischemia.

The intravitreal dose of ranibizumab was $0.5 \mathrm{mg} / 0.05 \mathrm{~mL}$, and that of aflibercept was $2 \mathrm{mg} / 0.05 \mathrm{~mL}$. Initially, the patients received three consecutive monthly injections of anti-VEGF drugs followed by pro re nata treatment until an improvement in the central macular edema was confirmed by OCT or until their visual acuity was stable.

\section{Statistical Analysis}

Statistical analyses were performed using a commercial statistical software package (JMP, ver. 11.0; SAS Institute, Cary, NC, USA). Existence of edema, disruption or disappearance of the ellipsoid zone (EZ) and external limiting membrane (ELM), and histories of PRP, sub-Tenon's capsule triamcinolone acetonide (STTA), cataract extraction, and vitrectomy were categorized as "no" or "yes," with the two variables coded as ordinal variables: 0 or 1 . We first used the Shapiro-Wilk test to determine whether the data were normally distributed. The Student $t$ test was used to evaluate baseline differences in age and HbAlc between pairs of groups. The Wilcoxon rank-sum test was used to evaluate differences in the baseline $\mathrm{CMT}$ and the number of injections between pairs of groups. Differences in the baseline BCVA between pairs of groups were tested by both Student $t$ test and Wilcoxon rank-sum test. We used the Fisher exact test to evaluate differences in the distributions of gender, the types of drugs administered, the types of edema, EZ status, ELM status, previous PRP, previous STTA, lens status, and previous vitrectomy between pairs of groups. Differences in the mean logMAR BCVA changes from baseline to month $12\left(\triangle \mathrm{BCVA}_{\mathrm{M} 12}\right)$ and differences in the mean CMT changes from baseline to month 12 $\left(\Delta \mathrm{CMT}_{\mathrm{M} 12}\right)$ between pairs of patient groups were compared using the Student $t$ test. The relationship between $\triangle \mathrm{BCVA}_{\mathrm{M} 3}$ and $\triangle \mathrm{BCVA}_{\mathrm{M} 12}$ was determined by the Pearson correlation coefficient. 
Table 1. Baseline characteristics of the patients

\begin{tabular}{|c|c|c|c|c|c|c|c|}
\hline & $\begin{array}{l}\text { All } \\
(n=25)\end{array}$ & \multicolumn{3}{|c|}{ Classification by $\Delta \mathrm{CMT}_{\mathrm{M} 3}$} & \multicolumn{3}{|c|}{ Classification by $\triangle \mathrm{BCVA}_{\mathrm{M} 3}$} \\
\hline Men/women & $7 / 13$ & $4 / 7$ & $4 / 10$ & $1.00^{\mathrm{b}}$ & $4 / 7$ & $4 / 10$ & $1.00^{\mathrm{b}}$ \\
\hline Glycated hemoglobin, \% & $6.56 \pm 0.74$ & $6.48 \pm 0.46$ & $6.63 \pm 0.92$ & $0.67^{\mathrm{a}}$ & $6.86 \pm 0.81$ & $6.39 \pm 0.68$ & $0.20^{\mathrm{a}}$ \\
\hline logMAR BCVA & $0.50 \pm 0.31$ & $0.43 \pm 0.32$ & $0.55 \pm 0.30$ & $\begin{array}{l}0.33^{\mathrm{a}} \\
0.26^{\mathrm{c}}\end{array}$ & $0.37 \pm 0.29$ & $0.60 \pm 0.30$ & $\begin{array}{l}0.06^{\mathrm{a}} \\
0.053^{\mathrm{c}}\end{array}$ \\
\hline Administrated drug (ranibizumab/aflibercept) & $15 / 10$ & $5 / 6$ & $10 / 4$ & $0.24^{\mathrm{b}}$ & $7 / 4$ & $8 / 6$ & $1.00^{\mathrm{b}}$ \\
\hline Sponge-like retinal swelling edema & $23(92 \%)$ & $10(91 \%)$ & $13(93 \%)$ & $1.00^{\mathrm{b}}$ & $11(100 \%)$ & $12(86 \%)$ & $0.49^{\mathrm{b}}$ \\
\hline Cystoid macular edema & $18(72 \%)$ & $7(64 \%)$ & $11(79 \%)$ & $0.66^{\mathrm{b}}$ & $8(73 \%)$ & $10(71 \%)$ & $1.00^{\mathrm{b}}$ \\
\hline Serous retinal detachment & $8(32 \%)$ & $3(38 \%)$ & $5(56 \%)$ & $1.00^{\mathrm{b}}$ & $3(27 \%)$ & $5(36 \%)$ & $1.00^{\mathrm{b}}$ \\
\hline Disruption or disappearance of the EZ & $19(76 \%)$ & $8(73 \%)$ & $11(76 \%)$ & $1.00^{\mathrm{b}}$ & $8(73 \%)$ & $11(76 \%)$ & $1.00^{\mathrm{b}}$ \\
\hline Disruption or disappearance of the ELM & $18(72 \%)$ & $6(55 \%)$ & $12(86 \%)$ & $0.18^{\mathrm{b}}$ & $6(55 \%)$ & $12(86 \%)$ & $0.18^{\mathrm{b}}$ \\
\hline
\end{tabular}

Values are presented as mean \pm standard deviation, $n / n$, or $n(\%)$. BCVA, best-corrected visual acuity; $\triangle \mathrm{BCVA} \mathrm{M}_{3}$, logMAR BCVA change from baseline to month 3; CMT, central macular thickness; $\triangle \mathrm{CMT}_{\mathrm{M} 3}$, CMT change from baseline to month 3; DRG, delayed responder group; ELM, external limiting membrane; EZ, ellipsoid zone; IRG, immediate responder group; logMAR, logarithm of the minimum angle of resolution; STTA, sub-Tenon's capsule triamcinolone acetonide; VIG, visual improvement group; VNIG, visual nonimprovement group. ${ }^{\mathrm{a}} t$ test. ${ }^{\mathrm{b}}$ Fisher exact test. ${ }^{\mathrm{c}}$ Wilcoxon rank-sum test.

Table 2. BCVA and CMT outcome at month 12

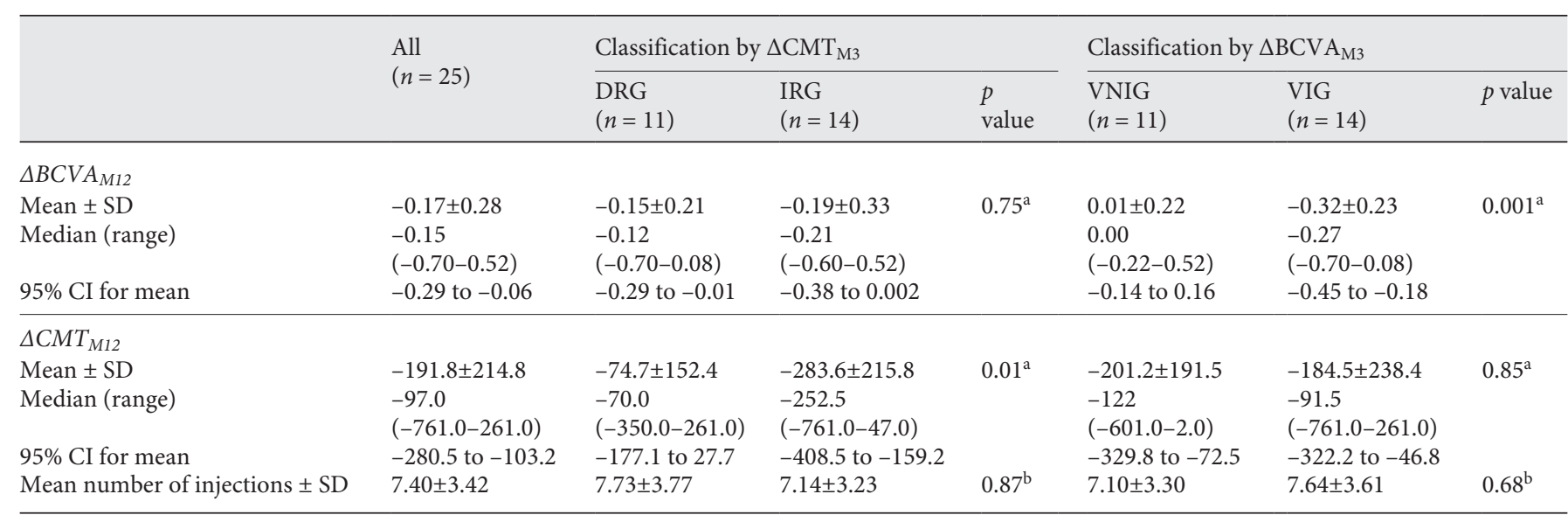

BCVA, best-corrected visual acuity; $\triangle \mathrm{BCVA}_{\mathrm{M} 3}$, logMAR BCVA change from baseline to month $3 ; \triangle \mathrm{BCVA}_{\mathrm{M} 12}$, logMAR BCVA change from baseline to month 12; CI, confidence interval; CMT, central macular thickness; $\Delta \mathrm{CMT}_{\mathrm{M} 3}, \mathrm{CMT}$ change from baseline to month 3; $\Delta \mathrm{CMT}_{\mathrm{M} 12}, \mathrm{CMT}$ change from baseline to month 12; DRG, delayed responder group; IRG, immediate responder group; SD, standard deviation; VIG, visual improvement group; VNIG, visual nonimprovement group. ${ }^{\mathrm{a}} \mathrm{t}$ test. ${ }^{\mathrm{b}}$ Wilcoxon rank-sum test.

We performed a multiple linear regression analysis to determine the independent association of $\triangle \mathrm{BCVA}_{\mathrm{M} 3}$ (an independent variable) with $\triangle \mathrm{BCVA}_{\mathrm{M} 12}$ (a dependent variable), adjusting for age, gender, baseline logMAR BCVA, and baseline CMT. Further, we performed a multiple stepwise regression analysis to determine which variables were associated with $\triangle \mathrm{BCVA}_{\mathrm{M} 12}$, including $\triangle \mathrm{BCVA}_{\mathrm{M} 3}, \triangle \mathrm{CMT}_{\mathrm{M} 3}$, and baseline variables as independent variables. We also evaluated the effect of anti-VEGF drug injections on BCVA in the two responder status groups based on the logMAR BCVA changes from baseline to month $1\left(\triangle \mathrm{BCVA}_{\mathrm{M} 1}\right)$ and month $2\left(\triangle \mathrm{BCVA}_{\mathrm{M} 2}\right)$. Missing values were assigned by using the last observation carried forward method. Differences were considered significant at $p<0.05$. 
Fig. 1. Effect of intravitreal anti-VEGF drug injections on the BCVA and CMT in the two responder status groups based on CMT changes from baseline after three injections of anti-VEGF drugs. a Mean $\triangle \mathrm{BCVA}_{\mathrm{M} 12}$ in the DRG and the IRG classified by CMT changes. b Mean $\triangle \mathrm{CMT}_{\mathrm{M} 12}$ in the DRG and the IRG classified by CMT changes. The Student $t$ test was used to compare the significance of differences between groups. BCVA, best-corrected visual acuity; $\triangle \mathrm{BCVA}_{\mathrm{M} 12}, \log \mathrm{MAR} B C V A$ change from baseline to month 12; CMT, central macular thickness; $\triangle \mathrm{CMT}_{\mathrm{M} 12}$, CMT change from baseline to month 12; DRG, delayed responder group; IRG, immediate responder group; logMAR, logarithm of the minimum angle of resolution; SE, standard error; VEGF, vascular endothelial growth factor.

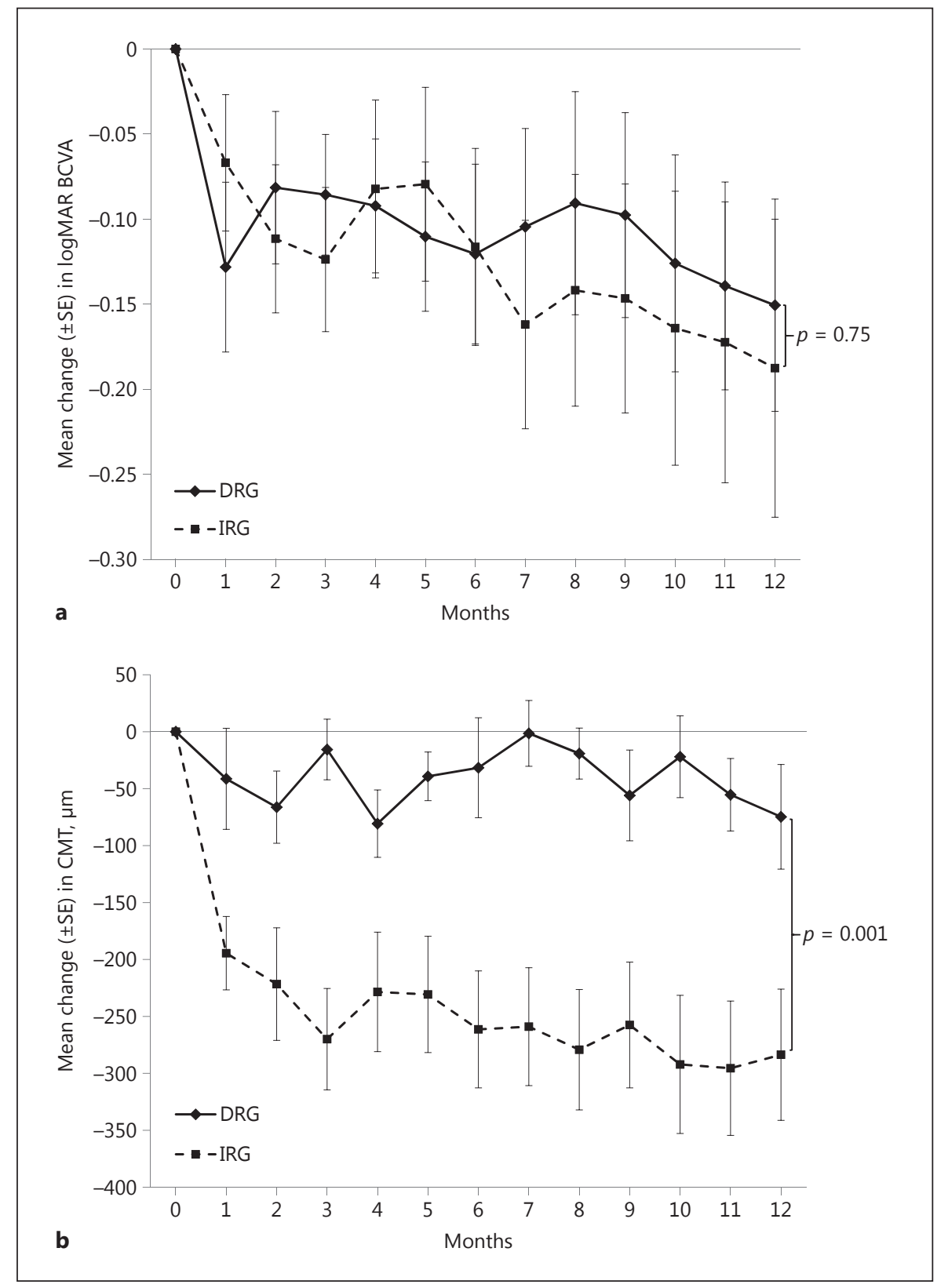

\section{Results}

The baseline characteristics of the patients are shown in Table 1. At baseline, age, gender distribution, glycemic control, baseline BCVA, type of drug administered, types of edema, EZ status, ELM status, lens status, and the distributions of previous PRP, STTA, and vitrectomy were not significantly different between the pairs of patient groups in either classification. The mean numbers of anti-VEGF drug injections at month 12 were not signifi- cantly different between the pairs of groups in either classification (Table 2).

\section{Classification by $\triangle C M T_{M 3}$}

The visual outcomes at month 12 in the classification by $\triangle \mathrm{CMT}_{\mathrm{M} 3}$ are shown in Table 2 and Figure 1a. In the $\mathrm{DRG}$, the mean $\pm \mathrm{SD}$ for BCVA was $0.43 \pm 0.32 \log \mathrm{MAR}$ units at baseline, $0.34 \pm 0.26 \log \mathrm{MAR}$ units at month 3 , and $0.28 \pm 0.22 \log$ MAR units at month 12 . In the IRG, the mean \pm SD for BCVA was $0.55 \pm 0.30 \log$ MAR units 
Fig. 2. Effect of intravitreal anti-VEGF drug injections on the BCVA and CMT in the two responder status groups based on $\log$ MAR BCVA changes from baseline after three injections of anti-VEGF drugs. a Mean $\triangle \mathrm{BCVA}_{\mathrm{M} 12}$ in the VIG and the VNIG in the classification by CMT changes. b Mean $\triangle \mathrm{CMT}_{\mathrm{M} 12}$ in the VIG and the VNIG classified by logMAR BCVA changes. The Student $t$ test was used to compare the significance of differences between groups. BCVA, best-corrected visual acuity; $\triangle \mathrm{BCVA}_{\mathrm{M} 12}$, logMAR BCVA change from baseline to month 12; CMT, central macular thickness; $\Delta \mathrm{CMT}_{\mathrm{M} 12}$, CMT change from baseline to month 12 ; logMAR, logarithm of the minimum angle of resolution; SE, standard error; VEGF, vascular endothelial growth factor; VIG, visual improvement group; VNIG, visual nonimprovement group.
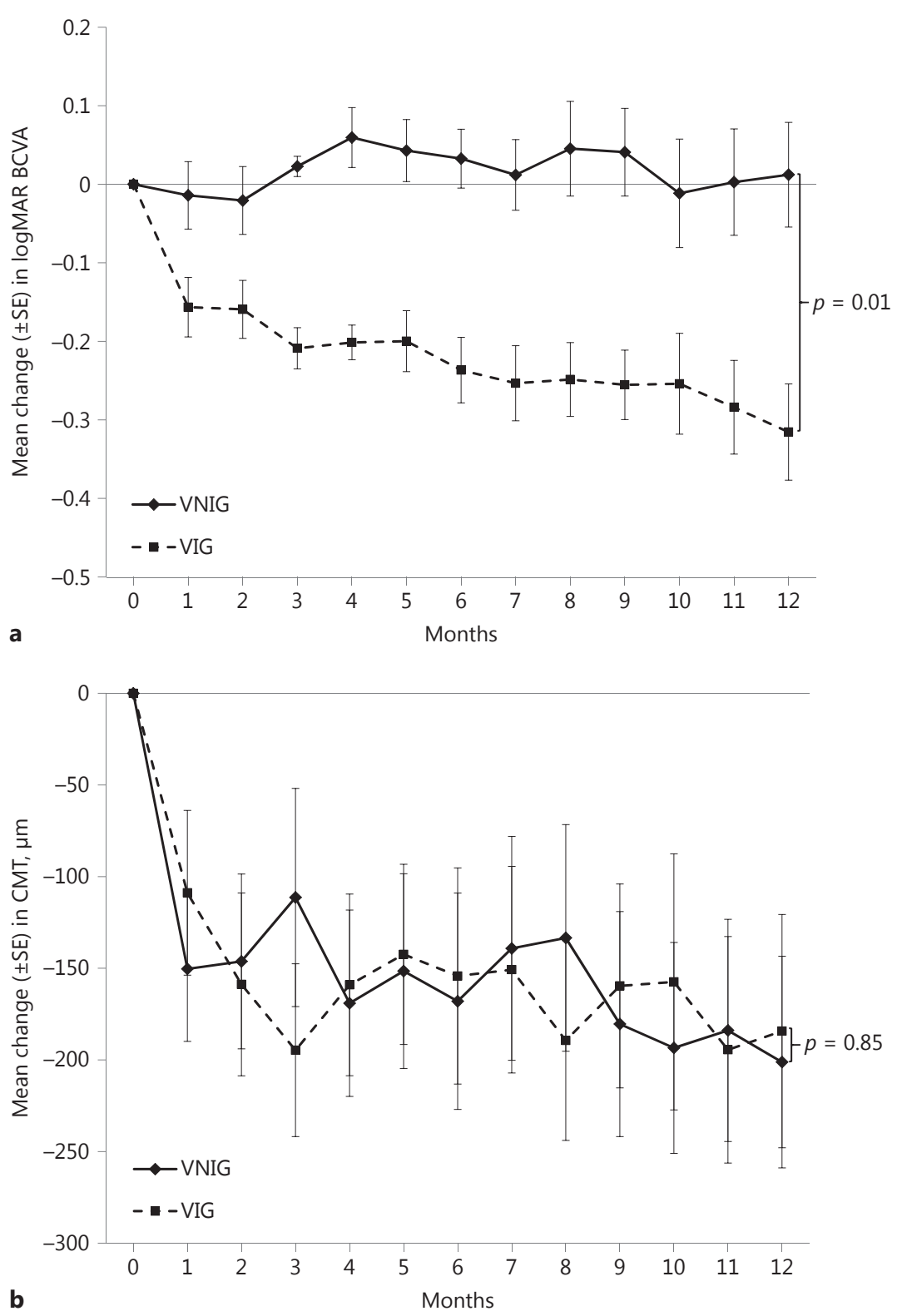

at baseline, $0.43 \pm 0.32 \log$ MAR units at month 3 , and $0.37 \pm 0.42 \log$ MAR units at month 12 .

At the 1-, 3-, and 12-month visits after the start of the anti-VEGF therapy, the DRG exhibited mean improvements of $-0.13,-0.09$, and $-0.15 \log$ MAR units, whereas the IRG had mean improvements of $-0.07,-0.12$, and $-0.19 \log$ MAR units (Fig. 1a). The visual acuity improvement was $-0.15 \log$ MAR units in the DRG and -0.19 $\log$ MAR units in the IRG at month 12 , and the difference was not significant ( $p=0.75$; Table 2 ).
The anatomic outcomes at month 12 in the classification by $\Delta \mathrm{CMT}_{\mathrm{M} 3}$ are shown in Table 2 and Figure $1 \mathrm{~b}$. The mean CMT improvement was $-74.7 \mu \mathrm{m}$ in the DRG and $-283.6 \mu \mathrm{m}$ in the IRG at month 12 , and the difference was significant $(p=0.01$; Table 2$)$.

\section{Classification by $\triangle B C V A_{M 3}$}

The visual outcomes at month 12 in the classification by $\triangle \mathrm{BCVA}_{\mathrm{M} 3}$ are shown in Table 2 and Figure $2 \mathrm{a}$. In the VNIG, the mean \pm SD for BCVA was $0.37 \pm 0.29 \log$ MAR 


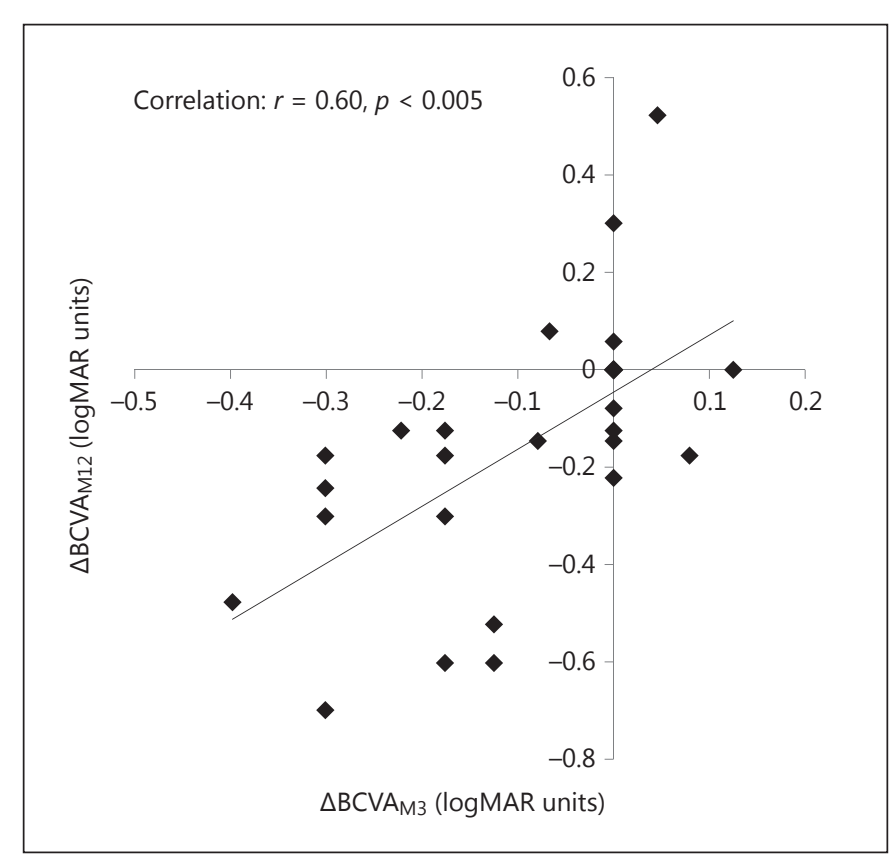

Fig. 3. Correlation between $\triangle \mathrm{BCVA}_{\mathrm{M} 3}$ and $\triangle \mathrm{BCVA} \mathrm{A}_{\mathrm{M} 12}$. BCVA, best-corrected visual acuity; $\triangle \mathrm{BCVA}_{\mathrm{M} 3}, \log \mathrm{MAR} B C V A$ change from baseline to month 3; $\triangle \mathrm{BCVA}_{\mathrm{M} 12}$, logMAR BCVA change from baseline to month 12 ; $\log M A R$, logarithm of the minimum angle of resolution.

units at baseline, $0.39 \pm 0.29 \log$ MAR units at month 3 , and $0.38 \pm 0.46 \operatorname{logMAR}$ units at month 12. In the VIG, the mean \pm SD for BCVA was $0.60 \pm 0.30 \log$ MAR units at baseline, $0.39 \pm 0.31 \log \mathrm{MAR}$ units at month 3 , and $0.29 \pm 0.23 \log$ MAR units at month 12 .

At the 1-, 3-, and 12-month visits after the start of anti-VEGF therapy, the VNIG showed mean improvements of $-0.01,0.02$, and $0.01 \operatorname{logMAR}$ units, whereas the VIG had mean improvements of $-0.16,-0.21$, and -0.32 $\log$ MAR units (Fig. 2a). At month 12, the visual acuity improvement was $0.01 \operatorname{logMAR}$ units in the VNIG and $-0.32 \log$ MAR in the VIG, and the difference was significant $(p<0.005$; Table 2$)$.

The anatomic outcomes at month 12 in the classification by $\triangle \mathrm{BCVA}_{\mathrm{M} 3}$ are shown in Table 2 and Figure $2 \mathrm{~b}$. The mean CMT improvement was $-201.2 \mu \mathrm{m}$ in the VNIG and $-184.5 \mu \mathrm{m}$ in the VIG at month 12 , and the difference was not significant ( $p=0.85$; Table 2 ).

The Pearson correlation coefficient showed a significant relationship between $\triangle \mathrm{BCVA}_{\mathrm{M} 3}$ and $\triangle \mathrm{BCVA}_{\mathrm{M} 12}(r=$ $0.60, p=1.67 \times 10^{-3}$; Fig. 3). We evaluated the associations of $\triangle \mathrm{BCVA}_{\mathrm{M} 3}$ (as an independent variable) with $\triangle \mathrm{BCVA}_{\mathrm{M} 12}$ (a dependent variable) in our calculation of regression coefficients $(\beta)$ using a multiple linear regression analysis.
After adjusting for age, gender, logMAR BCVA, and CMT at baseline, $\triangle \mathrm{BCVA}_{\mathrm{M} 3}$ was independently associated with $\triangle \mathrm{BCVA}_{\mathrm{M} 12}\left(\beta=1.10, p=9.35 \times 10^{-3}, 95 \%\right.$ CI $\left.0.30-1.89\right)$. There were no significant interactions between $\triangle \mathrm{BCVA}_{\mathrm{M} 12}$ and either age, gender, logMAR BCVA at baseline, or CMT at baseline (all $p>0.05$ ).

Multiple stepwise regression analysis revealed that $\triangle \mathrm{BCVA}_{\mathrm{M} 3}\left(\beta=1.25, p=7.22 \times 10^{-5}\right)$, previous vitrectomy $\left(\beta=0.28, p=1.05 \times 10^{-3}\right)$, previous PRP $(\beta=-0.15, p=$ $3.91 \times 10^{-2}$ ), and disruption or disappearance of the ELM $\left(\beta=-0.15, p=2.30 \times 10^{-3}\right)$ were independent predictors of $\triangle \mathrm{BCVA}_{\mathrm{M} 12}$ (online suppl. Table S1; for all online suppl. material, see www.karger.com/doi/10.1159/000481711).

We also evaluated the effect of injections of anti-VEGF drugs on the BCVA in the two responder status groups based on $\triangle \mathrm{BCVA}_{\mathrm{M} 1}$ and $\triangle \mathrm{BCVA}_{\mathrm{M} 2}$ (online suppl. Fig. $\mathrm{S} 1)$. The differences in the visual outcomes at month 12 between the two groups were not significant in either classification (month $1, p=0.11$; month $2, p=0.062$ ). The Pearson correlation coefficient results showed that $\triangle \mathrm{BCVA}_{\mathrm{M} 12}$ was significantly correlated with $\triangle \mathrm{BCVA}_{\mathrm{M} 1}$ $\left(r=0.57, p=2.95 \times 10^{-3}\right)$, but not with $\triangle \mathrm{BCVA}_{\mathrm{M} 2}(r=$ $0.36, p=7.42 \times 10^{-2}$ ).

No clinically significant complication was detected in any of the eyes.

\section{Discussion}

Our results showed that the differences in $\log$ MAR BCVA changes between the two groups were significant at month 12 in the classification by $\triangle \mathrm{BCVA}_{\mathrm{M}}$, but not in the classification by $\triangle \mathrm{CMT}_{\mathrm{M} 3}$. Moreover, a significant correlation between $\triangle \mathrm{BCVA}_{\mathrm{M} 3}$ and $\triangle \mathrm{BCVA}_{\mathrm{M} 12}$ was observed in this study. These results indicate that $\triangle \mathrm{BCVA}_{\mathrm{M} 3}$ may predict the visual outcome at month 12 in patients with DME.

In the classification by $\triangle \mathrm{CMT}_{\mathrm{M} 3}$, our findings were consistent with previous studies [19-21]. These results support continuing anti-VEGF therapy for DME even when patients have delayed anatomic response to treatment. In contrast, the between-group differences in the visual outcomes at month 12 were significant in the classification by $\triangle \mathrm{BCVA}_{\mathrm{M} 3}$. These findings indicate that the visual acuity changes in the early phase of treatment affect visual outcomes rather than the anatomic changes.

To further elucidate the possible reasons for the between-group differences by $\triangle \mathrm{BCVA}_{\mathrm{M} 3}$ in the visual outcomes at month 12, we considered differences in baseline BCVA. The baseline BCVA appeared to be better in the 
VNIG than in the VIG, although the difference was not statistically significant. In addition, there was no significant difference in BCVA at month 12 between the VNIG and the VIG ( $p=0.78$, Wilcoxon rank-sum test). Therefore, the lack of improvement in BCVA at month 12 in the VNIG might have been partly due to a floor effect, i.e., patients who started with lower logMAR BCVA had less room for improvement in logMAR BCVA. However, the results of the multiple linear regression analysis indicated that the significant positive association of $\triangle \mathrm{BCVA}_{\mathrm{M} 3}$ with $\triangle \mathrm{BCVA}_{\mathrm{M} 12}$ persisted even after adjustment by baseline BCVA. Moreover, the mean baseline logMAR BCVA in the VNIG was 0.37 (median 0.30 [ 20/50-20/40]), which was not sufficiently low for a floor effect and in fact provided ample room for improvement. We therefore concluded that the involvement of a floor effect in the present study was relatively limited.

The differences in the visual outcomes at month 12 were not observed in the classification by $\triangle \mathrm{BCVA}_{\mathrm{M} 1}$ and $\triangle \mathrm{BCVA}_{\mathrm{M} 2}$. Therefore, at least three administrations are required to detect the difference in visual outcomes, and the three consecutive monthly injections of anti-VEGF drugs followed by pro re nata treatment could be considered an effective method for each patient with DME.

Previous studies have shown significant interactions between baseline parameters and visual outcomes [2224]. The initial levels of BCVA and CMT are factors known to be associated with the visual and OCT outcomes after anti-VEGF therapy. In this study, $\triangle \mathrm{BCVA}_{\mathrm{M} 3}$ was independently associated with $\triangle \mathrm{BCVA}_{\mathrm{M} 12}$ after adjustment for these potential confounders.

The present study demonstrated discordance between visual and anatomic outcome, which was consistent with two previous studies $[19,20]$. These findings suggest that CMT change is just one of several variables affecting visual outcome. For example, if there is irreversible visual loss (such as photoreceptor cell damage), anatomic improvement may not contribute to visual improvement. In this study, we further investigated variables affecting visual outcome by using a multiple stepwise regression analysis (online suppl. Table $\mathrm{S} 1$ ). We found that $\Delta \mathrm{CMT}_{\mathrm{M} 3}$ was not a predictor of visual outcome at month 12 , while previous vitrectomy, previous PRP, and ELM status were predictors of visual outcome at month 12 in addition to $\triangle \mathrm{BCVA}_{\mathrm{M} 3}$. These factors may have contributed to the discordance between visual and anatomic outcome.

As shown in online supplementary Table S1, previous vitrectomy was positively correlated with $\triangle \mathrm{BCVA}_{\mathrm{M} 12}$, and previous PRP and disruption or disappearance of the ELM were negatively correlated with $\triangle \mathrm{BCVA}_{\mathrm{M} 12}$. This indicated that eyes with previous vitrectomy tended to show less improvement in visual acuity and that eyes with previous PRP or the disruption or disappearance of the ELM tended to show more improvement in visual acuity. Our previous studies suggested that an antiangiogenic shift occurs in the vitreous after vitrectomy and that the improvement is slower after intravitreal ranibizumab in patients with vitrectomized eyes $[25,26]$. This, in turn, would be expected to lead to a positive correlation with $\triangle \mathrm{BCVA}_{\mathrm{M} 12}$. As for previous PRP, it is possible that PRP might have reduced the VEGF level [27]. Such an effect could have conferred protection against photoreceptor cell damage caused by persistent DME, which might be the reason why the visual function was relatively recovered in eyes with previous PRP after edema reduction by anti-VEGF therapy. As for ELM status, the baseline BCVA in eyes with disruption or disappearance of the ELM was significantly worse than that in eyes with normal ELM ( $p=0.0087$, Wilcoxon rank-sum test). Therefore, there might have been a floor effect, such that eyes with normal ELM had less room for improvement in logMAR BCVA. However, since the present study included only a small number of subjects, further investigations will be needed to settle these points.

On the other hand, according to the results of the multiple stepwise regression analysis, the significant positive association of $\triangle \mathrm{BCVA}_{\mathrm{M} 3}$ with $\triangle \mathrm{BCVA}_{\mathrm{M} 12}$ persisted after adjustment for previous vitrectomy, previous PRP, and ELM status, which indicated that $\triangle \mathrm{BCVA}_{\mathrm{M} 3}$ was associated with $\triangle \mathrm{BCVA}_{\mathrm{M} 12}$ independently of previous vitrectomy, previous PRP, or ELM status. Therefore, our study revealed that $\triangle \mathrm{BCVA}_{\mathrm{M} 3}$ may be one of the major factors for predicting the prognosis of visual acuity in anti-VEGF treatment, and that the BCVA changes of patients such as those in the present VNIG would not be expected to improve with continuous administrations of anti-VEGF drugs. In consideration of these results, switching treatment to other options such as laser photocoagulation, combination therapy with steroid drugs, or vitrectomy should be considered for patients whose vision does not improve.

The limitations of this retrospective analysis include potential patient and treatment selection biases. Moreover, the small number of eyes may have attenuated the statistical power for detecting differences between the groups. As these factors may have biased our results, further prospective studies are needed.

In conclusion, the VIG showed significant improvement in BCVA compared with the VNIG. These results indicate that $\triangle \mathrm{BCVA}_{\mathrm{M} 3}$ may predict the visual outcome 
at month 12 in DME patients treated with anti-VEGF drugs. We suggest that for DME patients whose vision has not improved after three consecutive monthly injections of anti-VEGF drugs, switching therapy to another option should be considered in routine clinical practice.

\section{Acknowledgments}

This work was supported in part by JSPS KAKENHI grants No. 26293374, 26670757, 15H04995, and 16K15734.

\section{Statement of Ethics}

Our study was approved by the Institutional Ethics Committee of Kyushu University Hospital (Fukuoka, Japan) and was conducted in accordance with the tenets of the Declaration of Helsinki on biomedical research involving human subjects. All patients gave informed consent before their data were entered in the study.

\section{Disclosure Statement}

The authors declare no conflict of interest.

\section{References}

1 Varma R, Bressler NM, Doan QV, Gleeson M, Danese M, Bower JK, Selvin E, Dolan C, Fine J, Colman S, Turpcu A: Prevalence of and risk factors for diabetic macular edema in the United States. JAMA Ophthalmol 2014;132:1334-1340.

2 Mathew C, Yunirakasiwi A, Sanjay S: Updates in the management of diabetic macular edema. J Diabetes Res 2015;2015:794036.

3 Aiello LP, Avery RL, Arrigg PG, Keyt BA, Jampel HD, Shah ST, Pasquale LR, Thieme H, Iwamoto MA, Park JE, et al: Vascular endothelial growth factor in ocular fluid of patients with diabetic retinopathy and other retinal disorders. N Engl J Med 1994;331:1480-1487.

4 Antonetti DA, Barber AJ, Hollinger LA, Wolpert EB, Gardner TW: Vascular endothelial growth factor induces rapid phosphorylation of tight junction proteins occludin and zonula occluden 1. A potential mechanism for vascular permeability in diabetic retinopathy and tumors. J Biol Chem 1999;274:23463-23467.

5 Rajendram R, Fraser-Bell S, Kaines A, Michaelides M, Hamilton RD, Esposti SD, Peto T, Egan C, Bunce C, Leslie RD, Hykin PG: A 2-year prospective randomized controlled trial of intravitreal bevacizumab or laser therapy (BOLT) in the management of diabetic macular edema: 24 -month data: report 3. Arch Ophthalmol 2012;130:972-979.

6 Elman MJ, Bressler NM, Qin H, Beck RW, Ferris FL 3rd, Friedman SM, Glassman AR, Scott IU, Stockdale CR, Sun JK; Diabetic Retinopathy Clinical Research Network: Expanded 2-year follow-up of ranibizumab plus prompt or deferred laser or triamcinolone plus prompt laser for diabetic macular edema. Ophthalmology 2011;118:609-614.

7 Nguyen QD, Brown DM, Marcus DM, Boyer DS, Patel S, Feiner L, Gibson A, Sy J, Rundle AC, Hopkins JJ, Rubio RG, Ehrlich JS; RISE and RIDE Research Group: Ranibizumab for diabetic macular edema: results from 2 phase III randomized trials: RISE and RIDE. Ophthalmology 2012;119:789-801.
8 Lang GE, Berta A, Eldem BM, Simader C, Sharp D, Holz FG, Sutter F, Gerstner O, Mitchell P; RESTORE Extension Study Group: Two-year safety and efficacy of ranibizumab $0.5 \mathrm{mg}$ in diabetic macular edema: interim analysis of the RESTORE extension study. Ophthalmology 2013;120:20042012.

9 Diabetic Retinopathy Clinical Research Network, Elman MJ, Aiello LP, Beck RW, Bressler NM, Bressler SB, Edwards AR, Ferris FL 3rd, Friedman SM, Glassman AR, Miller KM, Scott IU, Stockdale CR, Sun JK: Randomized trial evaluating ranibizumab plus prompt or deferred laser or triamcinolone plus prompt laser for diabetic macular edema. Ophthalmology 2010;117:10641077.e35.

10 Nguyen QD, Shah SM, Khwaja AA, Channa R, Hatef E, Do DV, Boyer D, Heier JS, Abraham $P$, Thach AB, Lit ES, Foster BS, Kruger E, Dugel P, Chang T, Das A, Ciulla TA, Pollack JS, Lim JI, Eliott D, Campochiaro PA; READ-2 Study Group: Two-year outcomes of the Ranibizumab for Edema of the Macula in Diabetes (READ-2) study. Ophthalmology 2010;117:2146-2151.

11 Diabetic Retinopathy Clinical Research Network, Scott IU, Edwards AR, Beck RW, Bressler NM, Chan CK, Elman MJ, Friedman SM, Greven CM, Maturi RK, Pieramici DJ, Shami M, Singerman LJ, Stockdale CR: A phase II randomized clinical trial of intravitreal bevacizumab for diabetic macular edema. Ophthalmology 2007;114:1860-1867.

12 Mitchell P, Bandello F, Schmidt-Erfurth U, Lang GE, Massin P, Schlingemann RO, Sutter F, Simader C, Burian G, Gerstner O, Weichselberger A; RESTORE Study Group: The RESTORE study: ranibizumab monotherapy or combined with laser versus laser monotherapy for diabetic macular edema. Ophthalmology 2011;118:615-625.
13 Michaelides M, Kaines A, Hamilton RD, Fraser-Bell S, Rajendram R, Quhill F, Boos CJ, Xing W, Egan C, Peto T, Bunce C, Leslie RD, Hykin PG: A prospective randomized trial of intravitreal bevacizumab or laser therapy in the management of diabetic macular edema (BOLT study) 12-month data: report 2. Ophthalmology 2010;117:1078-1086.e2.

14 Arevalo JF, Sanchez JG, Fromow-Guerra J, Wu L, Berrocal MH, Farah ME, Cardillo J, Rodriguez FJ; Pan-American Collaborative Retina Study Group: Comparison of two doses of primary intravitreal bevacizumab (Avastin) for diffuse diabetic macular edema: results from the Pan-American Collaborative Retina Study Group (PACORES) at 12-month follow-up. Graefes Arch Clin Exp Ophthalmol 2009;247:735-743.

15 Do DV, Nguyen QD, Boyer D, Schmidt-Erfurth U, Brown DM, Vitti R, Berliner AJ, Gao B, Zeitz O, Ruckert R, Schmelter T, Sandbrink R, Heier JS; da Vinci Study Group: One-year outcomes of the da Vinci Study of VEGF Trap-Eye in eyes with diabetic macular edema. Ophthalmology 2012;119:16581665.

16 Schmid MK, Reich O, Faes L, Boehni SC, Bittner M, Howell JP, Thiel MA, Signorell A, Bachmann LM: Comparison of outcomes and costs of ranibizumab and aflibercept treatment in real-life. PLoS One 2015;10: e0135050.

17 Kiss S, Liu Y, Brown J, Holekamp NM, Almony A, Campbell J, Kowalski JW: Clinical utilization of anti-vascular endothelial growth-factor agents and patient monitoring in retinal vein occlusion and diabetic macular edema. Clin Ophthalmol 2014;8: 1611-1621.

18 Pieramici DJ, Wang PW, Ding B, Gune S: Visual and anatomic outcomes in patients with diabetic macular edema with limited initial anatomic response to ranibizumab in RIDE and RISE. Ophthalmology 2016;123:13451350. 
19 Brown DM, Nguyen QD, Marcus DM, Boyer DS, Patel S, Feiner L, Schlottmann PG, Rundle AC, Zhang J, Rubio RG, Adamis AP, Ehrlich JS, Hopkins JJ; RIDE and RISE Research Group: Long-term outcomes of ranibizumab therapy for diabetic macular edema: the 36-month results from two phase III trials: RISE and RIDE. Ophthalmology 2013;120:2013-2022.

20 Diabetic Retinopathy Clinical Research Network, Browning DJ, Glassman AR, Aiello LP, Beck RW, Brown DM, Fong DS, Bressler NM, Danis RP, Kinyoun JL, Nguyen QD, Bhavsar AR, Gottlieb J, Pieramici DJ, Rauser ME, Apte RS, Lim JI, Miskala PH: Relationship between optical coherence tomography-measured central retinal thickness and visual acuity in diabetic macular edema. Ophthalmology 2007;114:525-536.
21 Mushtaq B, Crosby NJ, Dimopoulos AT, Lip PL, Stavrou P, El-Sherbiny S, Yang Y: Effect of initial retinal thickness on outcome of intravitreal bevacizumab therapy for diabetic macular edema. Clin Ophthalmol 2014;8: 807-812.

22 Cheema HR, Al Habash A, Al-Askar E: Improvement of visual acuity based on optical coherence tomography patterns following intravitreal bevacizumab treatment in patients with diabetic macular edema. Int J Ophthalmol 2014;7:251-255.

23 Rayess N, Rahimy E, Ying GS, Bagheri N, Ho AC, Regillo CD, Vander JF, Hsu J: Baseline choroidal thickness as a predictor for response to anti-vascular endothelial growth factor therapy in diabetic macular edema. Am J Ophthalmol 2015;159:85-91.e1-e3.

24 Bressler SB, Qin H, Beck RW, Chalam KV, Kim JE, Melia M, Wells JA 3rd; Diabetic Retinopathy Clinical Research Network: Factors associated with changes in visual acuity and central subfield thickness at 1 year after treatment for diabetic macular edema with ranibizumab. Arch Ophthalmol 2012;130: 1153-1161.
25 Yoshida S, Nakama T, Ishikawa K, Arima M, Tachibana T, Nakao S, Sassa Y, Yasuda M, Enaida H, Oshima Y, Kono T, Ishibashi T: Antiangiogenic shift in vitreous after vitrectomy in patients with proliferative diabetic retinopathy. Invest Ophthalmol Vis Sci 2012;53:6997-7003.

26 Koyanagi Y, Yoshida S, Kobayashi Y, Kubo Y, Yamaguchi M, Nakama T, Nakao S, Ikeda Y, Ohshima Y, Ishibashi T, Sonoda KH: Comparison of the effectiveness of intravitreal ranibizumab for diabetic macular edema in vitrectomized and nonvitrectomized eyes. Ophthalmologica 2016;236:67-73.

27 Mohamed TA, Mohamed SE: Effect of panretinal laser photocoagulation on plasma VEGF, endothelin-1 and nitric oxide in PDR. Int J Ophthalmol 2010;3:19-22. 